in vivo $34: 2641-2646(2020)$

doi:10.21873/invivo.12082

\title{
VEGF-A Is Associated With the Degree of TILs and PD-L1 Expression in Primary Breast Cancer
}

\author{
TAKAAKI FUJII ${ }^{1,2}$, TOMOKO HIRAKATA ${ }^{1,2}$, SASAGU KUROZUMI $^{1,2}$, SHOKO TOKUDA $^{1,2}$, \\ YUKO NAKAZAWA $^{1,2}$, SAYAKA OBAYASHI ${ }^{1,2}$, REINA YAJIMA $^{1,2}$, TETSUNARI OYAMA $^{3}$ and KEN SHIRABE ${ }^{2}$ \\ ${ }^{1}$ Division of Breast and Endocrine Surgery, Graduate School of Medicine, Gunma University, Gunma, Japan; \\ ${ }^{2}$ Department of General Surgical Science, Graduate School of Medicine, Gunma University, Gunma, Japan; \\ ${ }^{3}$ Department of Diagnostic Pathology, Graduate School of Medicine, Gunma University, Gunma, Japan
}

\begin{abstract}
Background/Aim: Vascular endothelial growth factor-A (VEGF-A), an important angiogenic factor, has been reported to effect cancer growth and development. Recent reports indicated that anti-VEGF therapy has an important effect of enhancing anti-tumor immunity in various cancers. In the current study, we investigated the relationship between VEGF-A expression and immunological factors, including programmed cell death ligand $1(P D-L 1)$ and the degrees of stromal tumor-infiltrating lymphocytes (TILs) in breast cancer. Patients and Methods: This study enrolled 97 cases with invasive breast cancer who had undergone surgery without preoperative therapy. The grades of stromalTILs were evaluated using the criteria of the International Working Group for TILs in breast cancer: low, intermediate, and high. VEGF-A and PD-L1 positivity were evaluated by immunohistochemistry. The relationship between VEGF-A expression and the expression of PD-L1 and TILs was investigated. Results: Among the 97 cases, 37 (38.1\%) had positive VEGF-A expression in the breast tumor. We divided the cases in two groups based on the VEGF-A expression levels. The analysis revealed that $P D-L 1$ positivity was significantly associated with VEGF-A expression in the breast tumor (29.7\% vs. 10.0\%, $p=0.014)$. Among the cases with positive PD-L1, 36.7\% of VEGF-positive cases and none of VEGF-negative cases had low TILs in the breast tumor. Conclusion: VEGF-A expression in breast cancer may reflect PD-L1 expression in the tumor. VEGF-A may act as
\end{abstract}

This article is freely accessible online.

Correspondence to: Takaaki Fujii, MD, Ph.D., FACS Division of Breast and Endocrine Surgery, Department of General Surgical Science, Graduate School of Medicine, Gunma University, 3-39-22 Showa-machi, Maebashi, Gunma 371-8511, Japan. Tel: +81 0272208224, Fax: +81 0272208230, e-mail: ftakaaki@gunma-u.ac.jp

Key Words: VEGF-A, breast cancer, TILs, PD-L1. a negative biomarker of TILs in PD-L1-positive breast cancer. Our results suggest that VEGF-A may be predictive of immunological features and may serve as a useful biomarker for immuno-targeting therapy in patients with breast cancer.

Vascular endothelial growth factor-A (VEGF-A), one of the most important angiogenic factors (1-3), has been reported to effect cancer growth and development (3-6). VEGF-A is also involved in the regulation of immune response in various cancers $(3,7-14)$. Recent reports have indicated that anti-VEGF therapy has the important effect of enhancing anti-tumor immunity in various cancers $(3,7-14)$. The immune system affects tumor progression and dissemination, and treatment response (15-18). Immune cell infiltration has been observed in breast cancer tissue (15-18) and tumorinfiltrating lymphocytes (TILs) has been reported to reflect immunological characteristics in cancer tissue. Several studies have also aimed to elucidate the functions of TILs in cancer tissue and the immune response in cancer has been driven by the specific functions of TILs (19). Several recent clinical studies, including our study, revealed that TILs were a prognostic factor and predictor of the response to chemotherapy in patients with breast cancer (15-22). AntiVEGF targeting therapy has been reported to be involved in the regulation of immune responses and to increase the intratumoral infiltration of lymphocytes (7). Anti-VEGF therapy also enhanced the efficacy of immune checkpoint inhibitors in several cancer therapy $(8,9,12)$. We reported that programmed death-ligand 1 (PD-L1) expression was associated with the response to chemotherapy in cases with HER2-positive breast cancer (23). PD-L1 and PD-1 (programmed cell death protein-1) are considered immune checkpoint factors that eliminate T-cell activation and inhibit the immune reaction to cancer cells in a lot of cancers including breast cancer $(23,24)$. These factors have attracted attention as novel therapeutic targets in various types of cancers. However, it is unknown whether VEGF-A is related 
to these immunological features in breast cancer. In the current study, we investigated the relationships between VEGF-A expression and immunological factors, including PD-L1 and degrees of stromal TILs in breast cancer, which have been suggested to be prognostic factors or which may reflect immunological features in breast cancer.

\section{Patients and Methods}

We retrospectively investigated the ninety-seven cases with primary breast cancer (T1-4, N0-2, M0) at the Division of Breast and Endocrine Surgery, Graduate School of Medicine, Gunma University between June 2009 and February 2015. All 97 patients had undergone radical breast surgery. None of the patients had received preoperative chemotherapy. The exclusion criteria were as follows: bilateral breast cancer, previous treatment for breast cancer, presence of distant metastases, pregnancy or breastfeeding at the time of diagnosis, other current malignancies, diabetes mellitus, or severe cardiac, hematological, renal, pulmonary, or hepatic abnormalities. Patients with incomplete clinical information and male patients were excluded. All patients included in this study gave their informed consent at the time of surgery for inclusion in future analyses. All procedures performed in studies involving human participants were in accordance with the ethical standards of the Clinical Ethics Committee of Gunma University and with the Helsinki declaration.

The following clinical data were obtained: the patient's age, tumor TNM stage, and estrogen receptor (ER) expression status, progesterone receptor $(\mathrm{PgR})$ expression status, and the HER2 score of the primary tumor, nuclear grade (NG) and lymphovascular invasion. The ER and PgR statuses were assessed by the Allred score $\geq 3$ indicating positive of ER and $\operatorname{PgR}(25,26)$. HER2 overexpression was determined by immunohistochemistry analysis and a fluorescence in-situ hybridization (FISH) analysis with IHC $3+$ or IHC $2+$ /FISH+ indicating positive of HER2 (27). VEGF expression was assessed according to the percentage of immunoreactive cells in a total of 1,000 neoplastic cells using quantitative analysis. The cutoff between high and low VEGF-A expression was $25 \%$ of positive cancer cells using a polyclonal antibody against VEGF-A protein (A-20; 1/200 dilution; Santa Cruz Biotechnology, Dallas, TX, USA) (28). The proportional grades of stromal (Str)-TILs in surgical specimens were determined by pathologist as low (0-10\%), intermediate (20-40\%), and high (50$90 \%)$, using an immunohistochemistry method and the criteria of the International Working Group for TILs 2014 in breast cancer (29). PD-L1 (Abcam, ab208572, 1:200 dilution) was considered positive if expressed on at least $1 \%$ of tumor cells (i.e., a tumor proportion score $\geq 1 \%$ ) (30). Anti-CD8 antibodies (Abcam, ab4055, $1: 1,000$ dilution) were counted manually in 15 to 20 high-power fields. Intratumoral lymphocytes were graded by T-cells per highpower field as low ( $\leq 5)$, intermediate (6 to 19), or high $(\geq 20)(31)$.

Statistical analysis. The cases with breast cancer were divided into two groups: those with high expression of VEGF-A and those with low expression of VEGF-A in the breast cancer tissue. We conducted a univariate statistical analysis using the Fisher's exact test or the $c^{2}$ test with Yates' correction. To compare the two groups, Student's $t$-test was used. The analyses were carried out using the SPSS version 25 software (IBM, Chicago, IL, USA). Recurrence-
Table I. Patient clinicopathological characteristics depend on VEGF expression.

\begin{tabular}{lccc}
\hline & \multicolumn{2}{c}{ VEGF expression } & \multirow{2}{*}{$p$-Value } \\
\cline { 2 - 3 } & negative (n=60) & positive (n=37) & \\
\hline Age (years) (median) & $56.5(40-86)$ & $58.0(36-83)$ & 0.281 \\
$\mathrm{~T}$ & 29 & & \\
1 & 28 & 10 & 0.106 \\
2 & 3 & 1 & \\
$3 / 4$ & 24 & 7 & 0.025 \\
Lymph node & & & \\
involvement (n) & 52 & 33 & 0.488 \\
ER positive (n) & 49 & 29 & 0.442 \\
PgR positive (n) & 11 & 4 & 0.243 \\
HER2 positive (n) & & & \\
NG & 11 & 8 & 0.347 \\
1 & 30 & 13 & \\
2 & 19 & 16 & \\
3 & 29 & 15 & 0.590 \\
ly positive (n) & 11 & 7 & 0.638 \\
v positive (n) & & & \\
TILs & 38 & 18 & 0.360 \\
$\quad$ Low & 17 & 15 & \\
Intermediate & 5 & 4 & 0.014 \\
$\quad$ High & 6 & 11 & \\
PD-L1 positive (n) & & & \\
\hline
\end{tabular}

n, Number; NG, nuclear grade; TILs, tumor infiltrating lymphocytes, PD-L1, programmed death ligand.

free survival (RFS) was calculated using the Kaplan-Meier method. The log-rank test was used to evaluate differences between the recurrence-free intervals. Differences were considered significant when $p<0.05$.

\section{Results}

In this study, 97 patients with breast cancer were included in the analysis. Among all patients, $37(38.1 \%)$ had positive VEGF-A expression in the breast tumor. We divided the patients into two groups based on VEGF-A expression (Table I). All patients with high degrees of TILs showed high expression of CD8. The analysis revealed that positive expression of PD-L1 was significantly associated with VEGF-A expression (29.7\% vs. $10.0 \%, p=0.014$ ) in primary tumors. Expression of PD-L1 is used as companion diagnosis for immune checkpoint inhibitors in cancer therapy $(32,33)$. The degrees of TILs among patients with both PD-L1positive and VEGF-A-positive expression were low grade $36.7 \%$, intermediate grade $36.7 \%$, and high grade $27.3 \%$. On the other hand, those of TILs among patient with PD-L1positive and VEGF-A-negative expression were low grade $0 \%$, intermediate grade $50 \%$, and high grade $50 \%$. Among the cases positive for PD-L1, 36.7\% of VEGF-A-positive cases and none of the VEGF-A-negative cases had low TILs 
in the primary tumor. The RFS curves did not significantly differ between patients with high and low VEGF-A expression (data not shown).

\section{Discussion}

The immune system affects not only tumor growth, but also treatment response (15-18). PD-L1 expression is associated with immunological features of tumor and immune biomarkers. The key observations of the current study in cases with breast cancer are the following: (1) among various clinicopathological characteristics, VEGF-A expression was significantly associated with positive PD-L1 expression; (2) among the PD-L1-positive cases, 36.7\% of VEGF-A-positive cases had low TILs in the breast tumor, while none of the VEGF-A-negative cases had low TILs in the breast tumor. Our results suggest that VEGF-A expression is associated with PD-L1 and may be predictive of immunological features and biomarkers of immune checkpoint inhibitors in cases with breast cancer.

VEGF-A is one of the most important angiogenic factors that is strongly associated with the tumor immune microenvironment. There is a small but clear body of evidence associating VEGF-A or hypoxia-inducible factors with PD-L1 $(8,13,34)$. PD-L1 expression was associated with VEGF-A expression in clear cell renal carcinoma, and VEGF-A signaling is needed for PD-L1 up-regulation in tumor cells or M2 macrophages $(35,36)$. Furthermore, positive VEGF-A expression around the vessels was observed significantly more frequently in PD-L1-positive groups of patients with high-grade glioma and Hodgkin lymphoma $(13,37)$. These findings are consistent with our results that VEGF-A expression was significantly associated with PD-L1 positivity.

PD-L1 expression and the degree of TIL expression reflect the status of tumor immunological features (15-18). Lymphocytes are often observed around cancer tissue. These immune-related lymphocytes are associated with the proliferation and elimination of cancer cells, reflecting immunological reactions between cancer cells and lymphocytes. The state of TILs has been identified as a useful predictive marker for prognosis or response to cancer therapies in various types of cancers. TILs are composed of various types of immuno-related cells, and PD-1/PD-L1 immune check point pathway involves the tumor microenvironment (15-18). Expression of PD-L1 is used as a companion diagnostic tool for immune checkpoint inhibitors in cancer therapy $(32,33)$. Prospective trials to evaluate the efficacy of PD-1 and PD-L1 antibodies are ongoing in cases with several cancers, including breast cancer (38-40). PD-L1 is now a companion diagnostic tool of a PD-L1 inhibitor, atezolizumab, for the treatment of triple-negative breast cancer (33). In the present study, among the patients with positive PD-L1, some of the VEGFA-positive patients, but none of the VEGF-A-negative patients had low-grade TILs in the breast tumor. Higher levels of TILs present at diagnosis were associated with chemotherapy responsiveness $(15,17,41)$. Together, these past and present results imply the possibility that VEGF-A may reflect the status of PD-L1 expression and functions of TILs in breast cancer. These findings may provide evidence that VEGF-A is a potent predictor for determining adaptation for immune checkpoint therapy in cases with breast cancer.

Patients positive for both PD-L1 and VEGF-A have relatively higher rates of low TILs: although immune checkpoint inhibitors are not effective in such patients, and anti-VEGF therapy may be effective. As explained in the introduction section, anti-VEGF targeting therapy has been reported to be involved in the regulation of immune responses and in increased intratumoral infiltration of lymphocytes (7). Anti-VEGF therapy also enhanced the efficacy of immune checkpoint inhibitors in cancer therapy $(8,9,12)$. In cases with lung cancer, a combination of antiPD-1 and PD-L1 therapies and anti-VEGF therapies has been an effective treatment strategy $(3,7)$. Consistent with our findings, in those studies both VEGF-A and PD-L1 signaling blockade in cancer therapy was a successful strategy.

This preliminary study has potential limitations, including its retrospective design and the relatively small number of included patients $(n=97)$. However, to the best of our knowledge, this is the first report to describe the relationship between the expression of VEGF-A and the expression of PD-L1 in breast cancer. Additional studies are necessary to elucidate whether VEGF-A predict the immunological status in breast cancer tissue and VEGF-A is useful as a biomarker of immune checkpoint inhibitors in cases with breast cancer.

In conclusion, we demonstrated that VEGF-A expression in primary breast tumor reflected PD-L1 expression in the tumor. VEGF-A may act as a negative biomarker of TILs in PD-L1-positive breast cancer. In light of our results, VEGFA may reflect immunological features and is a useful biomarker for immunotargeting therapy in cases with breast cancer. Additional studies are needed to determine whether VEGF-A is a biomarker for immune checkpoint inhibitors in cases with breast cancer.

\section{Conflicts of Interest}

The Authors declare that they have no competing financial interests related to this study.

\section{Authors' Contributions}

TH analyzed data and TF wrote the initial draft of the manuscript. TF, TH, SK, ST, YN, SK, and RY collected data and were involved in the initial study conception and design. TF and KS interpreted the results and were involved in drafting the work and revising it 
critically for important intellectual content. TF approved the final version to be published. All Authors have read and approved the final manuscript.

\section{Acknowledgements}

The Authors would like to thank Ms. Kanai $\mathrm{H}$ for her secretarial assistance. This study is supported by Grants-in-Aid from the Japanese Ministry of Education, Culture, Sports, Science and Technology (T.F.).

\section{References}

1 Fujii T, Yonemitsu Y, Onimaru M, Tanii M, Nakano T, Egashira K, Takehara T, Inoue M, Hasegawa M, Kuwano H and Sueishi $\mathrm{K}$ : Nonendothelial mesenchymal cell-derived MCP-1 is required for FGF-2-mediated therapeutic neovascularization: critical role of the inflammatory/arteriogenic pathway. Arterioscler Thromb Vasc Biol 26(11): 2483-2489, 2006. PMID: 16960104. DOI: $10.1161 / 01 . A T V .0000244684 .23499 . b f$

2 Fujii T, Yonemitsu Y, Onimaru M, Inoue M, Hasegawa M, Kuwano $\mathrm{H}$ and Sueishi K: VEGF function for upregulation of endogenous PIGF during FGF-2-mediated therapeutic angiogenesis. Atherosclesosis 200(1): 51-57, 2008. PMID: 18258238. DOI: $10.1016 /$ j.atherosclerosis.2007.12.012

3 Hegde PS, Wallin JJ and Mancao C: Predictive markers of antiVEGF and emerging role of angiogenesis inhibitors as immunotherapeutics. Semm Cancer Biol 52(Pt 2): 117-124, 2018. PMID: 29229461. DOI: 10.1016/j.semcancer.2017.12.002

4 Fujii T, Yajima R, Tatsuki H, Oosone $\mathrm{K}$ and Kuwano $\mathrm{H}$ : Anticancer effect of rapamycin on MCF-7 via downregulation of VEGF expression. In Vitro Cell Dev Biol Anim 52(1): 45-48, 2016. PMID: 26427711. DOI: 10.1007/s11626-015-9944-5

5 Kim KJ, Li B, Winer J, Armanini M, Gillett N, Phillips HS and Ferrara N: Inhibition of vascular endothelial growth factorinduced angiogenesis suppresses tumour growth in vivo. Nature 362(6423): 841-844, 1993. PMID: 7683111. DOI: 10.1038/ $362841 \mathrm{a} 0$

6 Chiang KC, Yeh CN, Yeh TS, Juang HH, Chen LW, Kuo SF, Chen MH, Chen TC, Takano M, Kittaka A and Pang JS: MART10 , a $1 \alpha, 25(\mathrm{OH})_{2} \mathrm{D}_{3}$ analog, potently represses metastasis of $\mathrm{ER}^{+}$breast cancer cells with VEGF-A overexpression. Anticancer Res 38(7): 3879-3887, 2018. PMID: 28256614. DOI: 10.1038/srep43773

7 Gao F and Yang C: Anti-VEGF/VEGF2 monoclonal antibodies and their combinations with PD-1/PD-L1 inhibitors in clinic. Curr Cancer Drug Targets 20(1): 3-18, 2020. PMID: 31729943. DOI: $10.2174 / 1568009619666191114110359$

8 Lai YS, Wahyuningtyas R, Aui Sp and Chang KT: Autocrine VEGF signaling on M2 macrophages regulates PD-L1 expression for immunomodulation of T cells. J Cell Mol Med 23(2): 12571267, 2019. PMID: 30456891. DOI: 10.1111/jcmm.14027

9 Meder L, Schuldt P, Theien M, Schmitt A, Dietlein F, Klein S, Borchmann S, Wennhold K, Vlasic L, Oberbeck S, Riedel R, Florin A, Golfmann K, Schlober HA, Odenthal M, Buettner R, Wolf F, Hallek M, Herling M, won Bergwelt-Baildon M, Reinhardt HC and Ullrich RT: Combined VEGF and PD-L1 blockade displays synergistic treatment effects in an autochthonous mouse model of small cell lung cancer. Cancer
Res 78(15): 4270-4281, 2018. PMID: 29776963. DOI: 10.1158/ 0008-5472.CAN-17-2176

10 Koh YW, Lee SJ, Han JH, Haam S, Jung J, Lee HW: PD-L1 protein expression in non-small-cell lung cancer and its relationship with the hypoxia-related signaling pathways: A study based on immunohistochemistry and RNA sequencing data. Lung Cancer 129: 41-47, 2019. PMID: 30797490. DOI: 10.1016/j.lung can.2019.01.004

11 Lacal PM and Graziani G: Therapeutic implication of vascular endothelial growth factor receptor-1 targeting in cancer cells and tumor microenvironment by competitive and non-competitive inhibitors. Pharmacol Res 136: 97-107, 2018. PMID: 30170190. DOI: $10.1016 /$ j.phrs.2018.08.023

12 Georganaki M, van Hooren L and Dimberg A: Vascular targeting to increase the efficacy of immune checkpoint blockade in cancer. Front Immunol 9: 3081, 2018. PMID: 30627131. DOI: 10.3389/fimmu.2018.03081

13 Koh YW, Han JH, Yoon DH, Suh C and Huh J: PD-L1 expression correlates with VEGF and microvessel density in patients with uniformly treated classical Hodgkin lymphoma. Ann Hematol 96(11): 1883-1890, 2017. PMID: 28842748. DOI: 10.1007/s00277-017-3115-6

14 Zhang L, Chen Y, Li F, Bao L and Liu W: Atezolizumab and bevacizumab attenuate cisplatin resistant ovarian cancer cells progression synergistically via suppression epithelialmesenchymal transition. Front Immunol 10: 867, 2019. PMID: 31105696. DOI: 10.3389/fimmu.2019.00867

15 Kurozumi S, Inoue K, Matsumoto H, Fujii T, Horiguchi J, Oyama T, Kurosumi M and Shirabe K: Prognostic utility of tumor-infiltrating lymphocytes in residual tumor after neoadjuvant chemotherapy with trastuzumab for HER2-positive breast cancer. Sci Rep 9(1): 1583, 2019. PMID: 30733496. DOI: 10.1038/s41598-018-38272-1

16 Kurozumi S, Matsumoto H, Kurosumi M, Inoue K, Fujii T, Horiguchi J, Shirabe K, Oyama T and Kuwano H: Prognostic significance of tumour-infiltrating lymphocytes for estrogen receptor-negative breast cancer without lymph node metastasis. Oncol Lett 17(3): 2647-2656, 2019. PMID: 30867728. DOI: 10.3892/ol.2019.9938

17 Hirakata T, Fujii T, Kurozumi S, Katayama A, Honda C, Yanai K, Tokuda S, Nakazawa Y, Obayashi S, Yajima R, Kaira K, Oyama T and Shirabe K: FDG uptake relflects breast cancer immunological features: the PD-L1 expression and degree of TILs in primary breast cancer. Breast Cancer Res Treat 181(2): 331-338, 2020. PMID: 32253685. DOI: 10.1007/s10549-020-05619-0

18 Kurozumi S, Fujii T, Matsumoto H, Inoue K, Kurosumi M, Horiguchi J and Kuwano H: Significance of evaluating tumorinfiltrating lymphocytes (TILs) and programmed cell death-ligand 1 (PD-L1) expression in breast cancer. Med Mol Morphol 50(4): 185-194, 2017. PMID: 28936553. DOI: 10.1007/s00795-017$0170-\mathrm{y}$

19 Grivennikov SI, Greten FR and Karin M: Immunity, inflammation and cancer. Cell 140(6): 883-899, 2010. PMID: 20303878. DOI: 10.1016/j.cell.2010.01.025

20 Dieci MV, Criscitiello C, Goubar A, Viale G, Conte P, Guarneri V, Ficarra G, Mathieu MC, Delaloge S, Curigliano G and Andre F: Prognostic value of tumor-infiltrating lymphocytes on residual disease after primary chemotherapy for triple-negative breast cancer: a retrospective multicenter study. Ann Oncol 26(7): 1518, 2015. PMID: 26109735. DOI: 10.1093/annonc/mdv241 
21 Denkert C, von Minckwitz G, Brase JC, Sinn BV, Gade S, Kronenwett R, Pfitzner BM, Salat C, Loi S, Schmitt WD, Schem C, Fisch K, Darb-Esfahani S, Mehta K, Sotiriou C, Wienert S, Klare P, André F, Klauschen F, Blohmer JU, Krappmann K, Schmidt M, Tesch H, Kümmel S, Sinn P, Jackisch C, Dietel M, Reimer T, Untch M and Loibl S: Tumor-infiltrating lymphocytes and response to neoadjuvant chemotherapy with or without carboplatin in human epidermal growth factor receptor 2positive and triple-negative primary breast cancers. J Clin Oncol 33(9): 983-991, 2015. PMID: 25534375. DOI: 10.1200/ JCO.2014.58.1967

22 Adams S, Gray RJ, Demaria S, Goldstein L, Perez EA, Shulman LN, Martino S, Wang M, Jones VE, Saphner TJ, Wolff AC, Wood WC, Davidson NE, Sledge GW, Sparano JA, Badve SS: Prognostic value of tumor-infiltrating lymphocytes in triplenegative breast cancers from two phase III randomized adjuvant breast cancer trials: ECOG 2197 and ECOG 1199. J Clin Oncol 32(27): 2959-2966, 2014. PMID: 25071121. DOI: 10.1200/ JCO.2013.55.0491

23 Kurozumi S, Inoue K, Matsumoto H, Fujii T, Horiguchi J, Oyama T, Kurosumi M and Shirabe K: Clinicopathological values of PD-L1 expression in HER2-positive breast cancer. Sci Rep 9(1): 16662, 2019. PMID: 31723167. DOI: 10.1038/s41598019-52944-6

24 Ma W, Gilligan BM, Yuan J and Li T: Current status and perspectives in translational biomarker research for PD-1/PD-L1 immune checkpoint blockade therapy. J Hematol Oncol 9(1): 47, 2016. PMID: 27234522. DOI: 10.1186/s13045-016-0277-y

25 Harvey JM, Clark GM, Osborne CK, Allred DC: Estrogen receptor status by immunohistochemistry Is superior to the ligand-binding assay for predicting response to adjuvant endocrine therapy in breast cancer. J Clin Oncol 17(5): 14741481, 1999. PMID: 10334533. DOI: 10.1200/JCO.1999.17. 5.1474

26 Allred DC, Harvey JM, Berardo M and Clark GM: Prognostic and predictive factors in breast cancer by immunohistochemical analysis. Mod Pathol 11(2): 155-168, 1998. PMID: 9504686.

27 Wolff AC, Hammond ME, Hicks DG, Dowsett M, McShane LM, Allison KH, Allred DC, Bartlett JM, Bilous M, Fitzgibbons P, Hanna W, Jenkins RB, Mangu PB, Paik S, Perez EA, Press MF, Spears PA, Vance GH, Viale G and Hayes DF; American Society of Clinical Oncology; College of American Pathologists: Recommendations for human epidermal growth factor receptor 2 testing in breast cancer: American Society of Clinical Oncology/College of American Pathologists Clinical Practice Guideline Update. J Clin Oncol 31(31): 3997-4013, 2013. PMID: 24101045. DOI: 10.1200/JCO.2013.50.9984

28 Mineo TC, Ambrogi V, Baldi A, Rabitti C, Bollero P, Vincenzi $\mathrm{B}$ and Tonini G: Prognostic impact of VEGF, CD31, CD34, and CD105 expression and tumour vessel invasion after radical surgery for IB-IIA non-small cell lung cancer. J Clin Pathol 57(6): 591-597, 2004. PMID: 15166262. DOI: 10.1136/jcp. 2003.013508

29 Salgado R, Denkert C, Demaria S, Sirtaine N, Klauschen F, Pruneri G, Wienert S, Van den Eynden G, Baehner FL, PenaultLlorca F, Perez EA, Thompson EA, Symmans WF, Richardson AL, Brock J, Criscitiello C, Bailey H, Ignatiadis M, Floris G, Sparano J, Kos Z, Nielsen T, Rimm DL, Allison KH, Reis-Filho JS, Loibl S, Sotiriou C, Viale G, Badve S, Adams S, WillardGallo K, Loi S and International TILs Working Group 2014: The evaluation of tumor-infiltrating lymphocytes (TILs) in breast cancer: recommendations by an International TILs Working Group. Ann Oncol 26(2): 259-271, 2015. PMID: 25214542. DOI: $10.1093 /$ annonc/mdu450

30 Herbst RS, Baas P, Kim DW, Felip E, Pérez-Gracia JL, Han JY, Molina J, Kim JH, Arvis CD, Ahn MJ, Majem M, Fidler MJ, de Castro G Jr, Garrido M, Lubiniecki GM, Shentu Y, Im E, Dolled-Filhart $\mathrm{M}$ and Garon EB: Pembrolizumab versus docetaxel for previously treated, PD-L1-positive, advanced nonsmall-cell lung cancer (KEYNOTE-010): a randomised controlled trial. Lancet 387(10027): 1540-1550, 2016. PMID: 26712084. DOI: 10.1016/S0140-6736(15)01281-7

31 Zhang L, Conejo-Garcia JR, Katsaros D, Gimotty PA, Massobrio M, Regnani G, Makrigiannakis A, Gray H, Schlienger K, Liebman MN, Rubin SC and Coukos G: Intratumoral T Cells, recurrence, and survival in epithelial ovarian cancer. N Engl J Med 348(3): 203-213, 2003. PMID: 12529460. DOI: $10.1056 /$ NEJMoa020177

32 Larkin J, Chiarion-Sileni V, Gonzalez R, Grob JJ, Cowey CL, Lao CD, Schadendorf D, Dummer R, Smylie M, Rutkowski P, Ferrucci PF, Hill A, Wagstaff J, Carlino MS, Haanen JB, Maio M, Marquez-Rodas I, McArthur GA, Ascierto PA, Long GV, Callahan MK, Postow MA, Grossmann K, Sznol M, Dreno B, Bastholt L, Yang A, Rollin LM, Horak C, Hodi FS and Wolchok JD: Combined nivolumab and ipilimumab or monotherapy in untreated melanoma. N Engl J Med 373(1): 23-34, 2015. PMID: 26027431. DOI: 10.1056/NEJMoa 1504030

33 Schmid P, Adams S, Rugo HS, Schneeweiss A, Barrios CH, Iwata H, Diéras V, Hegg R, Im SA, Shaw Wright G, Henschel V, Molinero L, Chui SY, Funke R, Husain A, Winer EP, Loi S, Emens LA and IMpassion130 Trial Investigators: Atezolizumab and nab-paclitaxel in advanced triple-negative breast cancer. $\mathrm{N}$ Engl J Med 379(22): 2108-2121, 2018. PMID: 30345906. DOI: 10.1056/NEJMoa1809615

34 Kaira K, Shimizu K, Kitahara S, Yajima T, Atsumi J, Kosaka T, Ohtaki Y, Higuchi T, Oyama T, Asao T and Mogi A: 2-Deoxy2-(fluorine-18) fluoro-D-glucose uptake on positron emission tomography is associated with programmed death ligand-1 expression in patients with pulumonary adenocarcinoma. Eur J Cancer 101: 181-190, 2018. PMID: 30077123. DOI: 10.1016/ j.ejca.2018.06.022

35 Schmidinger M: Clinical decision-making for immunotherapy in metastatic renal cell carcinoma. Curr Opin Urol 28(1): 29-34, 2018. PMID: 29045250. DOI: 10.1097/MOU.0000000000000456

36 Wu X, Gionnie-Hurder A, Liao X, Connelly C, Connolly EM, Li J, Manos MP, Lawrence D, McDermott D, Severgnini M, Zhou J, Gjini E, Lako A, Lipschitz M, Pak CJ, Abdelrahman S, Rodig S and Hodi FS: Angiopoietin-2 as a biomarker and target for immune checkpoint therapy. Cancer Immunol Res 5(1): 1728, 2017. PMID: 28003187. DOI: 10.1158/2326-6066.CIR-160206

37 Xue S, Hu M, Li P, Ma J, Xie L, Teng F, Zhu Y, Fan B, Mu D and $\mathrm{Yu}$ J: Relationship between expression of PD-L1 and tumor angiogenesis, proliferation, and invasion in glioma. Oncotarget 8(30): 49702-49712, 2017. PMID: 28591697. DOI: 10.18632/ oncotarget.17922

38 Brahmer J, Reckamp KL, Baas P, Crinò L, Eberhardt WE, Poddubskaya E, Antonia S, Pluzanski A, Vokes EE, Holgado E, Waterhouse D, Ready N, Gainor J, Arén Frontera O, Havel L, Steins M, Garassino MC, Aerts JG, Domine M, Paz-Ares L, 
Reck M, Baudelet C, Harbison CT, Lestini B and Spigel DR: Nivolumab versus docetaxel in advanced squamous-cell nonsmall-cell lung cancer. N Engl J Med 373(2): 123-135, 2015. PMID: 26028407. DOI: 10.1056/NEJMoa1504627

39 Darvin P, Toor SM, Sasidharan Nair V and Elkord E: Immune checkpoint inhibitors: recent progress and potential biomarkers. Exp Mol Med 50(12): 165, 2018. PMID: 30546008. DOI: 10.1038/s12276-018-0191-1

40 Hersom $\mathrm{M}$ and Jørgensen JT: Companion and complementary diagnostics-focus on PD-L1 expression assays for PD-1/PD-L1 checkpoint inhibitors in non-small cell lung cancer. Ther Drug Monit 40(1): 9-16, 2018. PMID: 29084031. DOI: 10.1097/ FTD.0000000000000460
41 Loi S, Michiels S, Salgado R, Sirtaine N, Jose V, Fumagalli D, Kellokumpu-Lehtinen PL, Bono P, Kataja V, Desmedt C, Piccart MJ, Loibl S, Denkert C, Smyth MJ, Joensuu H and Sotiriou C: Tumor infiltrating lymphocytes are prognostic in triple negative breast cancer and predictive for trastuzumab benefit in early breast cancer: results from the FinHER trial. Ann Oncol 25(8): 1544-1550, 2014. PMID: 24608200. DOI: 10.1093/annonc/ mdu 112

Received May 21, 2020

Revised June 5, 2020

Accepted June 6, 2020 